\title{
Discussion
}

\section{Reply to comment on "Evaluation of a physically based quasi-linear and a conceptually based nonlinear Muskingum methods" by Reza Barati}

\author{
Muthiah Perumal $^{\mathrm{a}}$, Gokmen Tayfur ${ }^{\mathrm{b}, *}$, C. Madhusudana Rao ${ }^{\mathrm{c}}$, Gurhan Gurarslan ${ }^{\mathrm{d}}$ \\ a Department of Hydrology, Indian Institute of Technology Roorkee, Roorkee 247667, India \\ ${ }^{\mathrm{b}}$ Department of Civil Engineering, Izmir Institute of Technology, Izmir, Turkey \\ ${ }^{c}$ Department of Civil Engineering, National Institute of Technology, Jamshedpur 831014, India \\ ${ }^{\mathrm{d}}$ Department of Civil Engineering, Pamukkale University, Denizli, Turkey
}

The writers thank the discusser for his interest in the study of Perumal et al. (2017) and welcome the opportunity to address the issues raised by the discusser. The discusser has mainly raised four issues on the comparative study carried out by Perumal et al. (2017) in evaluating the performances of the VPMM model and the NLM based models, which was initiated by Gill $(1977,1978)$. These four issues are addressed by these writers in the following pages:

As a first issue, the discusser has raised a question about the appropriateness of using the VPMM model (Perumal and Price, 2013), which he considers as the much improved routing model of the Muskingum-Cunge family approach, and the original nonlinear Muskingum model of Gill (1978), which he, perhaps, considers as a initial version of the NLM models. These writers perceive that the discusser intends to convey that the performance evaluation study presented by Perumal et al. (2017) based on a latest improved model and a initial version of the NLM models is inappropriate. Before discussing straightaway on this issue, the writer would like to clarify on the misconception of the discusser in categorizing the VPMM method and the Muskingum-Cunge method under one family approach.

In developing the storage equation of the classical Muskingum method, McCarthy (1938) used the heuristic assumption that the storage of the routing reach can be considered to consist of a combination of prism and wedge storages resulting in the storage equation expressed in terms of linear weighted discharge of inflow and outflow of the reach. However, Cunge (1969) interpreted the Muskingum model by discarding the heuristic assumption employed by McCarthy (1938) for describing the storage equation as discussed above, and argued that the Muskingum model developed based on a one-to-one relationship between stage and discharge in a channel reach is not theoretically capable of exhibiting attenuation, but attributed the attenuation exhibited by it to the numerical diffusion of its routing equation. To quote herein in words of Cunge (1969):

\footnotetext{
* Corresponding author

E-mail addresses: p_erumal@yahoo.com (M. Perumal), gokmentayfur@iyte.edu. tr (G. Tayfur), madhu_chintalacheruvu@yahoo.co.in (C. Madhusudana Rao).
}

"Hence, while the $H(Q)$ relationship is assumed to be one-to-one, it is pointless to try to explain the damping effect of the Muskingum method by wedge or prism storage in the river."

Cunge (1969) further reasoned that matching of this numerical diffusion with the physical diffusion leads to the interpretation of the Muskingum method parameters in terms of flow and channel characteristics. Therefore, it is clear that the theory envisaged in the classical Muskingum model by McCarthy (1938) is distinctly different from that of the theory envisaged behind the development of the Muskingum-Cunge model (Cunge, 1969). In this context it is pointed out that the VPMM model proposed by Perumal and Price (2013) justifies the heuristic assumption employed by McCarthy (1938) for the development of storage equation based on hydrodynamic principle.

To elaborate further on this aspect that the storage in a given Muskingum reach can be expressed as $S=\Delta x A_{M}$, where $A_{M}$ is the flow area at any time at the midsection of the reach (Fig. 1 of Perumal et al., 2017) during unsteady flow. By expressing the normal discharge, $Q_{o M}$ corresponding to flow depth $y_{M}$, at the midsection of the reach, in the form of linear weighted discharge of instantaneous inflow, $I$ at the inlet of the reach, and the outflow, $Q$ at the outlet of the reach based on hydrodynamic principles, Perumal and Price (2013) expressed the reach storage as

$S=\Delta x A_{M}=\Delta x\left(\frac{Q_{o M}}{V_{o M}}\right)=\frac{\Delta x}{V_{o M}}[\theta I+(1-\theta) Q]$

where, $\theta=0.5-\mathrm{Q}_{\mathrm{oM}} / 2 \mathrm{~S}_{0} \mathrm{~B}_{\mathrm{M}} \mathrm{C}_{\mathrm{oM} \Delta \mathrm{x}}$, the weighting parameter of the Muskingum model.

Perumal and Price (2013) showed that Eq. (1) clearly expresses the approximate form of momentum equation of the Saint Venant equations governing the one-dimensional unsteady flow in channels, and it represents the storage equation of the classical Muskingum model. Therefore, it is erroneous to state that the VPMM method proposed by Perumal and Price (2013) pertains to that of the Muskingum-Cunge family approach. It may be noted that many approaches for interpreting the classical Muskingum method and subsequent establishment of its parameters $K$ and $\theta$ with flow and channel characteristics are available in literature. Perumal 
et al. (2015) provide a comprehensive review of these different approaches.

Now coming to the actual issue raised by the discusser, he finds fault with the approach followed by Perumal et al. (2017) for the comparative evaluation of the performances of the VPMM method with that of the NLM based methods which employ the approach of calibration using different parameter evaluation methods and subsequent validation of these calibrated models on the independent data set. It is appropriate to paraphrase the discusser statements in this regard.

"However, they applied the original nonlinear Muskingum model of Gill (1978). That is while NLM model was significantly improved in recent years, and all the improvements were neglected by Perumal et al. (2017). These are a lot of studies were focused on parameter estimation of the nonlinear Muskingum model..."

The above paraphrased comments raised by the discusser clearly suggests that he failed to understand the spirit behind the development of the study by Perumal et al. (2017) (as given in the 25th line of first column of page 438) which is again re-emphasized herein:

"Though the NLM method characterized by an additional parameter has increased the flexibility of the method...flood wave propagation process."

Gill $(1977,1978)$ attributed the reason for proposing the NLM method to the inability of the storage equation of the classical Muskingum model to simulate the nonlinearity of the channel routing process. So he proposed the nonlinear storage equation by simply raising the linear weighted discharge of storage equation of the classical Muskingum method by an exponent ' $m$ '. However, the storage equation of the classical Muskingum model given by Eq. (1) has hydrodynamic basis and the parameters $K$ and $\theta$ of this equation are related to channel and flow characteristics as described by Perumal and Price (2013). What Eq. (1) describes in the routing process is that for a given reach storage of an instantaneous unsteady flow scenario in a channel reach, as shown in Fig. (1) of Perumal et al. (2017), there is a corresponding steady flow scenario given by the linear weighted discharge $[\theta I+(1-\theta) Q]$ having the same reach storage as that of the corresponding unsteady flow. With varying parameters of $K$ and $\theta$ as per the relationship given by Perumal and price (2013) this equivalence of storage between unsteady and the steady flow scenarios are maintained throughout the routing process of the given inflow hydrograph in the channel reach and, thereby, the VPMM method is able to model the nonlinearity in the routing process. Of course, the maintenance of the equivalent storage between the unsteady and steady flow scenario is subjected to the applicability criterion of $\left(1 / S_{o}\right) \partial y / \partial x \ll 1$ estimated for the inflow hydrograph, which was found to be $\left(1 / S_{0}\right) \partial y / \partial x \leqslant 0.5$, both from theoretical as well as numerical experiments consideration. Beyond this applicability criterion, one has to resort to the use of improved hydrodynamics methods, such as the numerical solutions using the diffusive/ dynamic wave models. So this interpretation of the storage equation of the classical Muskingum model with ability to vary the parameters $K$ and $\theta$ at every time level to account for nonlinearity in the routing process emphasises the need to discontinue the study based on nonlinear storage equation proposed by Gill $(1977,1978)$. As the genesis of research on nonlinear Muskingum model was initiated based on the nonlinear storage equation proposed by Gill $(1977,1978)$ and the subsequent, so called, "improved nonlinear Muskingum models" were developed based on Gill's nonlinear storage equation, Perumal et al. (2017) considered it appropriate to study only the performance of Gill's NLM method with that of the VPMM method for comparative evaluation as the other "improved" variants of the NLM method were developed based on the NLM method of Gill $(1977,1978)$.

Further, many of the hydrologic routing methods, such as the Muskingum model, and lag and route model (Dooge and O'Kane, 2003) were developed in the pre-computer era for their use in the context of design flood studies required for many river valley projects and these models served their intended purpose by accounting the translation and attenuation characteristics of a flood wave in a lumped manner which are, however, intrinsically accounted in a distributed manner in hydraulic routing methods, such as the four-point finite difference method (NERC, 1975). Therefore, the VPMM method characterized by two parameters, accounting for translation and attenuation of flood wave in a lumped manner at any given instant of time, the linkage of these parameters with the channel and flow characteristics based on hydrodynamic principles, is more desirable than the multi parameter nonlinear routing models developed based on the NLM model of Gill $(1977,1978)$ or its latter variants with more than three parameters. Of course, the parameters of this model simply act only as tuning parameters without having any explicit relationship with channel and flow characteristics.

The second issue raised by the discusser questions the appropriateness of comparing the results of the VPMM and NLM models studied, especially, when the former method uses the known or the correct values of the Manning's roughness coefficient(s) in the considered channel reaches, while such advantage is not available to the NLM model. In this regard, it is to be noted that the VPMM model also could have been used as a calibration model, if the benchmark solutions used in this study are given without knowing the Manning's roughness coefficients used for arriving at the benchmark solutions. In such a situation, the parameter to be calibrated is only the reach averaged Manning's roughness coefficient without knowing the main channel and floodplain channel roughness characteristics. But the same fact holds good even for a fully physically based hydraulic routing method, if the channel cross-section details are not given a priori, but only a set of inflow and outflow hydrograph details are available. To underscore this problem, it is to be accepted that there exists no "truly physically based" routing method which does not require any calibration. In a theoretically strict sense, the variation of roughness characteristics in a channel reach is three dimensional which is difficult to model and, therefore, there is a need to establish a single parameter as a roughness coefficient by calibration process of matching the routing results, in case only one set inflow and the corresponding outflow hydrographs are given for the considered channel reach. While uncertainty prevails in a physically based routing methods with reference to the variability of roughness characteristics in a given channel reach, but the uncertainty related to the NLM based methods are many fold due to number of parameters used in the development of the NLM model which are simply used only as tuning parameters to enable close reproduction of the observed (benchmark) discharge hydrograph given at the outlet of the reach by the considered routing model without considering their relationship with channel and flow characteristics. While discussing in the latter part of the second issue, the discusser questions the logic behind the comparison of the VPMM model which does not use the calibration and subsequent verification steps, while the NLM model requires the use of calibration and verification steps. This was exactly the intention of Perumal et al. (2017) to undertake such a study to demonstrate that the approximate form of the momentum equation of the Saint Venant equations, under the condition $\left(\left(1 / S_{0}\right) \partial y / \partial x \leqslant 0.5\right)$, can be reduced to the form of the classical Muskingum storage equation which can be conveniently exploited to account for nonlinear characteristics of flood wave movement in channels and rivers using the VPMM model, 
proposed by Perumal and Price (2013), rather than employing a three-parameter NLM model proposed by Gill $(1977,1978)$ or by the discusser. In nutshell, the writers in their study (Perumal et al., 2017) demonstrated that the VPMM model proposed by Perumal and Price (2013) adopts the same form of storage equation as employed by McCarthy (1938) in the classical Muskingum model with the parameters $K$ and $\theta$ linked to the channel and flow characteristics which enable to vary these parameters with time and, thereby, account for nonlinearity of the flood wave movement process closely as built-in in the solution of the full Saint Venant equations. In other words, within the applicability limit, the results of the VPMM method are very close to that of the full dynamic wave solutions. Even when the channel reach characteristics, such as reach geometry, Manning's roughness coefficient and bed slope of the reach are given, the NLM model cannot make effective use of these details for better routing simulation purposes as no established relationships of the parameters of the method with channel and flow characteristics are available. Therefore, comparative evaluation of these methods as carried out by Perumal et al. (2017) is logically appropriate and correct. The writers would like to reiterate that there is no necessity to employ a semi-empirical based NLM storage equation based routing models which require complicated calibration and verification processes involving many parameters which do not have any physical meaning, but act only as tuning parameters.

The writers ponder over the third issue raised by the discusser on the consideration that the VPMM model requires more input information than the NLM model as these information may not be available in the study area. How the discusser thinks that the inflow and outflow hydrograph required for the calibration of the NLM models are obtained without knowing the stage, the associated flow area and the associated velocity corresponding to either the measured or estimated discharges at the inlet and outlet of the reach? Estimated average velocity corresponding to a given flow depth enables the estimation of the Manning's roughness coefficient at that flow depth. Knowing the details of cross-section geometry at upstream and downstream sections of the reach enables the estimation of bed slope information.

So when discharge information at upstream and downstream sections are available, all the associated information related to channel characteristics are also known. So there is no special effort required for collecting this information required for the solution of the VPMM model or that of the Saint Venant equations. By raising this issue, whether the discusser wants to claim that the NLM model is better than the VPMM model or that based on the numerical solution of the Saint Venant equations?

As a last issue, the discusser questions the results of the calibration step. The writers have verified these results once again carefully on the points raised by the discusser and confirm the correctness of the results given in the paper of Perumal et al. (2017).

Considering the straight forward explanation for the use of the classical Muskingum storage equation and its subsequent use for accounting nonlinearity in the routing process based on the theory behind the VPMM model (Perumal and Price, 2013), these writers are of the opinion that the sustained use of the NLM model, however, improved they may be, cannot be justified. In conclusion, based on the above discussions made on the issues raised by the discusser, these writers justify the comparative evaluation study conducted by Perumal et al. (2017) on the NLM and VPMM models. Further, they would like to emphasise that the VPMM model cannot be considered under the category of Muskingum-Cunge family approach.

\section{References}

Cunge, J.A., 1969. On a subject of a flood propagation method (Muskingum method). J. Hydraul. Res. 7 (2), 205-230.

Dooge, J.C.I., O'Kane, J.P., 2003. Deterministic Methods in Systems Hydrology. A Balkema Publishers.

Gill, M.A., 1977. Routing of floods in river channels. Nord. Hydrol. 8, 163-170.

Gill, M.A., 1978. Flood routing by the muskingum method. J. Hydrol. 36, 353-363. McCarthy, G.T., 1938. The unit hydrograph and flood routing. Conference of North Atlantic Div., U.S. Army Corps of Engineers.

Natural Environment Research Council, 1975. Flood studies report, Vol. III-Flood routing studies, Lodon, UK.

Perumal, M., Price, R.K., 2013. A fully volume conservative variable parameter McCarthy-Muskingum method: Theory and Verification. J. Hydrol. 502, 89-102.

Perumal, M., Sahoo, B., Moramarco, T., 2015. Interpretation of the Muskingum flood routing method: A historical perspective. In: Moramarco, T., Barbetta, S., Brocca, L. (Eds.), Chapter 10 in Advances in Watershed Hydrology. Water Resources Publications, LLC, Highlands, Ranch, Colarado, USA.

Perumal, M., Tayfur, G., Madhusudana, R.C., Gurarslan, G., 2017. Evaluation of a physically based quasi-linear and a conceptually based nonlinear Muskingum methods. J. Hydrol. 546, 437-449. 